\title{
COMPARATIVE STUDY BETWEEN THREE DIMENSIONAL TRANSVAGINAL ULTRASONOGRAPHY (3D) AND HYSTEROSCOPY IN ABNORMAL UTERINE BLEEDING
}

\author{
Nassar. A. M. ${ }^{* *}$ Salem H. H. * Aboshady Y. ${ }^{* * *}$ Hassanin M. S. ${ }^{*}$, Sultan $M^{*}$; \\ Kandil I. *, Abdel Aziz H. A. **** \\ *Department of Obstetrics \& Gynecology- Faculty of Medicine- Al-Azhar Universtiy. \\ ** International Islamic Center of population studies and Research - Department of Obstetrics \& \\ Gynecology, Al-Azhar University. \\ *** Department of Obstetrics and Gynecology Faculty of Medicine - Al-Azhar University (Assiutt branch) \\ **** El Galaa Teaching Hospital.
}

\section{ABSTRACT}

Objective : To compare three-dimensional transvaginal sonography (3D-TVS) (non invasive) and hysteroscopy (minimally invasive) as a diagnostic tool in patients suffering from abnormal uterine bleeding (AUB).

Design : A prospective randomizcd comparative study.

Setting : This study has been conducted in the Obstetrics and Gynecology department at Bab-Al Shaarial, Al-Azhar University Hospitals - Al Azhar University, from March 2003 to May 2005.

Patients \& Methods : One hundred and thirty patients complaining of abnormal uterine bleeding were investigated by $3 \mathrm{D}$ transvaginal ultrasound and hysteroscopy. Data obtained were recorded, correlated and statistically analyzed.

Results : Both hysteroscopy and 3D-TVS showed 100\% sensitivity and specificity in diagnosing atrophic endometrium and suspecting malignancy. However, in cases of hyperplasia, 3D-TVS had the same 100\% sensitivity but less specificity than hysteroscopy. On the other hand, in cases of polyps 3D-TVS had less sensitivity and specificity than hysteroscopy.

Conclusion : Both hysteroscopy (minimally invsasive) and 3D-TVS have the same accuracy in diagnosing atrophic endometrium and suspected malignancy, but Hysterescopy is superior than 3D-TVS in diagnosing hyperplasia and polyps in patients suffering from AUB.

\section{INTRODUCTION}

Abnormal uterine bleeding is an alarming symptom that requires accurate diagnosis in order to exclude cervical and endometrial diseases. While a definitive set of clinical methods are available for diagnosis and screenig of cervical pathologies, those concerning endometrial disease are still debated (1). The most common technique to obtain endometrial sample is $\mathrm{D} \& \mathrm{C}$, which has limitations due to significant diagnostic failure, invasiveness and high costs ${ }^{(2)}$.

3D dimensional ultrasound can visualize the three orthogonal planes at the same time. It can be used to observe any spatial axis and any angle of the endometrial cavity at the same time as well as to measure endometrial volume (3).

Endometrial hyperplasia appears as a well-defined, thick reflective layer occupying the whole uterine cavity. Thickened endometrium, 
enlarged uterine cavity, lobular uterus with mixed echo pattern and fluid uterine cavity all are sonographic findings suggestive of endometrial carcinoma ${ }^{(4)}$.

Hysteroscopy is a well-tolerated, accurate and sensitive procedure, which allows direct visualization and biopsy of diffuse or focal lesions in the endometrium ${ }^{(5)}$.

Hyperplastic endometrium appears hysteroscopically as thickened, congested and polypoid endometrium. Because of the plasticity of the endometrium determination of the thickness of the endometrium is simply made by pressing the endoscope against the uterine wall, this will leave a furrow by which the depth of the endometrium can be assessed ${ }^{(6)}$.

The most frequent polyps diagnosed by hysteroscopy in the uterine cavity are :

Mucous polyps: they are pseudopolyps, which occur as a part of an endometrial hyperplastic process, they are small, less than $1 \mathrm{~cm}$, sessile, and have structures that are identical to the surrounding endometrium. They are only seen in the secretory phase and will disappear with menstruation. True mucous polyps are permanent and persist in the proliferative phase. They may be pedunculated or non-pedunculated, mobile and they are larger than $1 \mathrm{~cm}$ in diameter. The appearance is similar to that of the surrounding endometrium, but they are frequently hyper congested. Fibroid polyps are usually pedunculated, smooth, mobile and difficult to be squeezed with the optic, with poorly identifiable glandular orifices.

Hysteroscopic appearance of endometrial atrophy is described as thin and pale yellow appearance of the endometrium with superficial areas of bleeding ${ }^{(7)}$.

\section{PATIENTS \& METHODS}

One hundred and thirty women complaining of abnormal uterine bleeding were recruited in this study from the Outpatient Gynecology Clinic in Bab Al-Shaaria University Hospital, Al Azhar University from May 2003 to May 2005.

All patients were in the age range from ( 45 to 52 years old) as most cases of abnormal uterine bleeding are in this age group. All patients-were submitted to complete history taking stressing on hormonal replacement therapy, systemic disease, and/or previous gynecological lesions.

General and local examinations were done to assure absence of any organic lesions. Laboratory investigation included complete blood picture, hematocrite, coagulation profile, hepatic and renal function tests.

Conventional 2D ultrasonic scanning was done to exclude any organic lesions. Formal consent had been taken from the patients after councelling them about the study details.

Patients receiving hormonal therapy (e.g. combined pills, progesterone only pills, medicated devices; contraceptive implants, injectable) were excluded from the study as well as patients with manifest pathology such as ovarian cysts or fibroid were excluded.

All patients underwent (3D) transvaginal ultrasound scan to measure the endometrial volume with a diagnostic criteria and interpretation of endometrial pattern.

1) Endometrial thickness of $3-5 \mathrm{~mm}$ and volume from 1 to $6 \mathrm{ml}$ as normal endometrium.

2) Thin smooth endometrium with a volume less than $1 \mathrm{ml}$ as atrophic endometrium. 
3) Thick, congested and/or polypoidal endometrium with a volume between $7-12 \mathrm{ml}$ as hyperplastic endometrium.

Hysteroscopic examination under general anesthesia, was then done using the $30^{\circ}$ lense to visualize and explore the whole uterine cavity and then a guided biopsy was taken and sent for histopathology to confirm the diagnosis expected by 3D ultrasound and hysteroscopy.

Data obtained were collected, compared and statistically analyzed.

\section{RESULTS}

Out of 130 cases investigated by 3D-TVS, 37 (28.46\%) cases revealed normal endometrium; 23 cases $(17.69 \%)$ showed atrophic endometrium; 20 cases $(15.38 \%)$ revealed endometrial polyps, 43 patients $(33.08 \%)$ diagnosed as hyperplasia and 7 cases $(5.4 \%)$ were suspected as endometrial malignancy (Table I).

Out of the 130 patients investigated by hysteroscopy and the results ensured by directed biopsy, 40 patients $(30.77 \%)$ showed normal endometrial findings. Histopathology results of these patients showed proliferative endometrium. Twenty three patients $(17.69 \%)$ revealed atrophic endometrium. twenty five patients (19.23\%) showed endometrial polyps, thirty five patients $(26.92 \%)$ revealed endometrial hyperplasia, and seven patients $(5.38 \%)$ had been suspected as having endometrial carcinoma that was proved by histopathology (Table II).

The sensitivity and Specificity of 3D-TVS to diagnose atrophic endometrium and to suspect malignancy was $100 \%$, and sensitivity of $100 \%$ but $96.67 \%$ specificity to diagnose hyperplasia. Its sensitivity to diagnose polyps was only $80 \%$ while its specificity was $100 \%$ (Table III).

The hysteroscopy showed a sensitivity and specificity of $100 \%$ in diagnosis of atrophic endometrium, hyperplasia and endometrial polyps as well as in suspecting malignancy (Table IV).

Table I : 3D -TVS Compared to Histopathology .

\begin{tabular}{|l|c|c|}
\hline \multicolumn{1}{|c|}{ Diagnosis } & $\begin{array}{c}\text { 3D-TV diagnosis } \\
\mathbf{n}(\%)\end{array}$ & $\begin{array}{c}\text { Histopathology } \\
(\%)\end{array}$ \\
\hline No abnormality & $37(28.46 \%)$ & $40(30.77 \%)$ \\
\hline Atrophic endometrium & $23(17.69 \%)$ & $23(17.69 \%)$ \\
\hline Endometrial hyperplasia & $43(33.08 \%)$ & $35(26.92 \%)$ \\
\hline Endometrial polyps & $20(15.38 \%)$ & $25(19.23 \%)$ \\
\hline Suspicious of malignancy & $7(5.38 \%)$ & $7(5.38 \%)$ \\
\hline Total number of patients & 130 & 130 \\
\hline
\end{tabular}


Table II : Hysteroscopic Findings Compared to Histopathology .

\begin{tabular}{|l|c|c|}
\hline \multicolumn{1}{|c|}{ Diagnosis } & $\begin{array}{c}\text { Hysteroscopy } \\
\mathbf{n}(\%)\end{array}$ & $\begin{array}{c}\text { Histopathology } \\
\mathbf{n}(\%)\end{array}$ \\
\hline No abnormality & $40(30.77 \%)$ & $40(30.77 \%)$ \\
\hline Atrophic endometrium & $23(17.69 \%)$ & $23(17.69 \%)$ \\
\hline Endometrial hyperplasia & $35(26.92 \%)$ & $35(26.92 \%)$ \\
\hline Endometrial polyps & $25(19.23 \%)$ & $25(19.23 \%)$ \\
\hline Suspicious of malignancy & $7(5.38 \%)$ & $7(5.38 \%)$ \\
\hline Total number of patients & 130 & 130 \\
\hline
\end{tabular}

Table III : Sensitivity and Specificity of 3D-TVS in Diagnosis of AUB .

\begin{tabular}{|l|c|c|c|c|c|c|}
\hline \multicolumn{1}{|c|}{ Diagnosis } & TP & FP & FN & TN & $\begin{array}{c}\text { Sensitivity } \\
\text { (TP/TP + FN) }\end{array}$ & $\begin{array}{c}\text { Specificity } \\
\text { (TN/TN + FP) }\end{array}$ \\
\hline Atrophic endometrium & 23 & 0 & 0 & 107 & $100 \%$ & $100 \%$ \\
\hline Polyps & 20 & 0 & 5 & 105 & $80 \%$ & $100 \%$ \\
\hline Hyperplasia & 40 & 3 & 0 & 87 & $100 \%$ & $96.67 \%$ \\
\hline Suspicious of malignancy & 7 & 0 & 0 & 123 & $100 \%$ & $100 \%$ \\
\hline
\end{tabular}

Table IV : Sensitivity and Specificity of Hysteroscopy in Diagnosis of AUB .

\begin{tabular}{|l|c|c|c|c|c|c|}
\hline \multicolumn{1}{|c|}{ Diagnosis } & TP & FP & FN & TN & $\begin{array}{c}\text { Sensitivity } \\
\text { (TP/TP + FN) }\end{array}$ & $\begin{array}{c}\text { Sensitivity } \\
\text { (TN/TN + FP) }\end{array}$ \\
\hline Atrophic endometrium & 23 & 0 & 0 & 107 & $100 \%$ & $100 \%$ \\
\hline Polyps & 25 & 0 & 0 & 105 & $100 \%$ & $100 \%$ \\
\hline Hyperplasia & 35 & 0 & 0 & 95 & $100 \%$ & $100 \%$ \\
\hline Suspicious of malignancy & 7 & 0 & 0 & 123 & $100 \%$ & $100 \%$ \\
\hline
\end{tabular}

\section{DISCUSSION}

Abnormal vaginal bleeding is the most common reason for women to undergo an interventional gynecologic procedure. In the past 10 years, the treatment of dysfunctional uterine bleeding has evolved considerably. Although dilatation and curettage was once the procedure of choice, hysteroscopy has proved to be a more reliable method in evaluating the endometrium, and many cases that were considered dysfunctional are now known to have harbored previously unidentified 
lesions as a cause for the vaginal bleeding. As sonography has proved to be a safe and noninvasive method for evaluating the endometrial cavity, transvaginal sonography has become the accepted technique for depicting and differentiating normal from abnormal endometrium ${ }^{(8)}$.

Hysteroscopy offered a reliable method for assessing intrauterine pathology ${ }^{(9)}$.

Ultrasonography is a fairly accurate method that has been used for studying the endometrium. With high freguency transvaginal sonography the endometrium can be easily visualized. It produces clear uterine image because of the proximity of the vaginal probe to the uterus. The endometrial echogenicity is likely to be due to the presence of glands and mucin, the frequently hypoechoic halo might possibly be related to a network of veins and capillaries around the muscle fibers in the inner layer of the myometrium ${ }^{(4)}$.

Transvaginal sonography (TVS) is an excellent diagnostic tool for some gynecologic disease. Several studies have shown a relationship between endometrial thicknesses as measured by TVS and endometrial abnormalities in women with postmenopausal bleeding (10-14).

In this study, 3D-TVS could diagnose malignancy by $100 \%$ sensitivity and specificity and with the same accuracy as Hysteroscopy. These results are in agreement with Gull et al. (15). who did not miss endometrial cancer by transvaginal sonographic measurements of endometrial thickness. Also, Campele and Tailot (16) proved that the endometrial volume in pathological conditions of the endometrium is significantly increased than among nonpathological conditions of the endometrium. Malinova and Pehlivanov (17) reported that the sensitivity of TVS for carcinoma varied according to the thickness of the endometrium used to distinguish normal from abnormal and the specificity for endometrial carcinoma was greater with higher cut off values for endometrial thickness.

Regarding endometrial hyperplasia; our study proved that 3D-TVS has sensitivity of $100 \%$ but the specificity was of $96.67 \%$ wtih mean endometrial volume measured of $12.9 \mathrm{ml}$. This result is in agreement with those of Gruboek (18) who stated that endometrial volume is significantly higher in endometrial hyperplasia than in endometrial polyp. This difference could not be shown by simple endometrial thickness measurements.

In the present study, diagnosis of atrophic endometrium by 3D-TVS was $100 \%$ sensitive and specific. there were neither false positive nor false negative results. This was in agreement with Fleischer et al., (4) who described atrophic endometrium in postmenopausal women as subtle linear rim measureing 2-3 $\mathrm{mm}$ by sonography, however mucus trapped within the lumen may give a sonographic impression of a thickened endometrium.

In the present study; the sensitivity of 3D-TVS was much less $(80 \%)$ in diagnosing endometrial polyps with false negative results that is to say there was a $20 \%$ chance of missing cases of polyps. These results are in agreement with that of Emanuel et al. ${ }^{(19)}$ and Dijkhuizen et al. ${ }^{(20)}$. This sensitivity could be improved by injecting saline in the cavity to delinate the polyp. Laifer et al. (8) also, found that transvaginal sonography was not a screening procedure of sufficient diagnostic value in symptomatic patients with abnormal uterine bleeding. De Kroon et al. (21) concluded that Three-dimensional saline infusion sonography (SIS) is valid and reliable in women suspected of having intrauterine abnormalities and may indeed have a relevant clinical value in addition to conventional saline infusion sonography (SIS). 


\section{CONCLUSION}

Both hysteroscopy (minimally invasive) and 3D-TVS have the same accuracy in diagnosing atrophic endometrium and suspected malignancy. But Hysterescopy is superior than 3D-TVS in diagnosing hyperplasia and polyps in patients suffering from AUB.

\section{REFERENCES}

1- Loverro G. Bettocchi S, Cormio G, Nicolardi V, and Greco P.: transvaginal sonography and hysterescopy in postmenopausal uterine bleeding Maturitas (1999) 33: 139-144.

2- Grimes D. A.: Diagnostic dilatation and curettage: a reappraisal. Am J. Obstet. Gynecol (1982) 158: 489-492.

3- Shipley, C.F. Smith, S. D. and Dennis, E.J.: Evaluation of pretreatment transvaginal ultrasonography in the management of patients with endometrial carcinoma. Am. J. Obstet. Gynecol. (1993) 167: 406.

4- Fleischer, A. C., Gordon, N. A. and Stephene.: Transvaginal sonography of the endometrium. Current and potential clinical applications. In: the principles and practice of ultrasonography in Obstetrics and gynecology. 4th ed. (eds): Fleischer $\mathrm{AC}$, Rornero $\mathrm{R}$, and Manning $\mathrm{FaO}$. Prentice-Hall International Inc. USA, (1991) P 583.

5- Lof FDdth ra e bleedng: the value f negatie stric vi. Obstet Gynecol (1989) 73: 16-20.

6- Hamou, J. E.: Microhysteroscopy Clin. obstet. Gynecol. (1983) 26 (2): 285.

7- Hamou, J. E. and Taylor, P. J.: Hysteroscopy and postmenopausal bleeding In: hysterosco;y and microcolop hysteroscopy text and Atlas. CR Craig Percy (ed.) copy right by Appleton Lange. A publishing Division of prentice Hall (1991) p. 26, $43,55,81,99$.

8- Laifer-Narin S., Nagesh Ragavendra, Evelyn K. Parmenter and Edward G. Grant : False-Normal Appearance of the Endometrium on Conventional Transvaginal Sonography Comparison with Saline Hysterosonography. A. J. R; (2002) 178: 129-133.

9. Dejong P, Doel F, and Falconer A.: Outpatinet diagnostic hysteroscopy. Br. J. Obstet Gynecol (1990) 97: 299-303.

10- Osmer R, Volksen M, Schauer A. : endometrial carcinoma Lancet (1990) 87 1569-1571.
11- Grandberg S, Wickland $M$ and Karelsson B.: Endometrial thickness as measured by endovaginal ultrasound for identifying endometrial abnormalities. Am J Obstet Gynecol (191) 164: 47-52.

12- Dorum A, Kristensen B, Langebrekke A, Sornes T and Skarr $O$.: Evaluation of endometrial thickness measured by endovaginal ultrasound in women with postmenopausal bleeding. Acta Obstet Gynecol Scand (1993) 72: 116-119.

13. Karlsson B, Granberg $S$, and Wilkland $M$. transvaginal ultrasonography of the endometrium in women with postmenopausal bleeding - a Nordic multicenter study. Am J Obstet Gynecol (1995) 172: 1488-1494.

14- Ferrazi E, Torri V, Trio D, and Zinnini E: Sonographic endometrial thickness: a useful test to predict atrophy in patients with postmenopausal bleeding. An Italian multicenter sludy. Ultrasound Obstet Gynecol (1996) 7: 315-321.

15- Gull B, Karla son B, Milo I, and Greenberg S.: Can ultrasound rplace diatation and curettage? A longitudinal evaluation of postmenopausal bleeding and transvaginal sonographic measurement of the endometrium as predictor of endometrial cancer. Am J Obstet Gynecol (2003) 188: 401-408.

16- Campbell, S. and Tailor, A: The diagnostic value of endometrial thickness and volume measurements by three dimensional ultrasound in patients with postmenopausal bleeding. Ultrasound Obstet. Gynccol (1996), 8. 272.

17- Malinova $M$. and Pehlivanov B.: Transvaginal sonography and endometrial thickness in patients with postmenopausal bleeding. E. J. Obstct Gynecol and Reprod Biol (1995) 58: 161-165.

18- Gruboeck K, Jurkovic D, Lowton F, Bauer B Zosmer N, Campell S.: Endometrial thickness and volume in paticnts with postmenopausal bleeding. Ultrasound obstet Gynecol; (1994) 4: 157-I60.

19. Emanuel MH, Verdel MJ, Wamsteker K, Lammes FB: A prospective comparison of transvaginal ultrasonography and diagnostic hysteroscopy in the evaluation of patients with abnormal uterine bleeding: clinical implications. Am J Obstet Gynccol; (1995) 172: 547-552.

20- Dijkhuizen FP, Brolmann HA, Potters AE, Bongers MY, Heinz AP.: The accuracy of transvaginal ultrasonography in the diagnosis of endometrial abnormaities. Obstet Gynecol; (1996) 87: 345-349.

21- De Kroon, C., Leonie A. Louwe, Baptist Trimbos, and Frank Willem Jansen : The Clinical Value of 3-Dimensional Saline Ifusion Sonography in Addition to 2-Dimensional Saline Infusion Sonography in Women with Abnormal Uterine Bleeding. J Ultrasound Med (12004) 23: $1433-1440$. 